\title{
CUESTIONES DISCUTIDAS Y DISCUTIBLES: TÉRMINO DE LA EMPRESA Y TÉRMINO DEL FUERO SINDICIAL
}

\author{
ROBERTO CERÓN REYES \\ JORGE MARTÍNEZ RIVERA* \\ Universidad de Chile
}

\section{PRELIMINARES}

La perplejidad ante la lectura de la sentencia de la Corte de Apelaciones de Punta Arenas ${ }^{1}$, que obligó a la Inspección del Trabajo a requerir la disolución de un sindicato luego que esta rechazara hacerlo previa solicitud administrativa, nos llamó a reflexionar sobre las normas de disolución de estas organizaciones pues se hacía necesario establecer si era la vía extraordinaria de la acción de protección la única posible para poner fin a un sindicato fantasma y abusivo. ¿Acaso el Derecho del Trabajo no contemplaba una solución? -nos preguntamos-.

En las siguientes líneas pretendemos abordar con extensión proporcionada un abanico de situaciones cuyo sustrato general es el reconocimiento de la libertad sindical.

En el plano internacional, su consagración se encuentra contenida en los convenios 87 y 98 de la OIT, dictados en el año 1948 y 1949, respectivamente; y ratificados en Chile en 2000. Asimismo, el ordenamiento jurídico nacional, en virtud de lo dispuesto en los artículos 5 y $19 \mathrm{~N}^{\circ} 19$ de la constitución, comprende la aplicación de tales convenios, por su asimilación bajo la forma de tratados internacionales y su protección expresa como garantía constitucional ${ }^{2}$.

Por su parte, la doctrina nacional ha conceptualizado la libertad sindical como aquel "derecho de los trabajadores y sus agrupaciones para organizarse y defender sus intereses"3. Natural resulta entonces que la organización de base más idónea para la defensa de tales intereses sea el sindicato. PALOMEQUE lo define como "la organización permanente de tra-

\footnotetext{
*Ayudantes del Departamento de Derecho del Trabajo y de la Seguridad Social, Facultad de Derecho, Universidad de Chile. Comentarios y sugerencias: roberto.ceron@derecho.uchile.d y/o jorge.martinez@derecho.uchile.cl

${ }^{1}$ Causa Rol 98-2009, sentencia de 10 de febrero de 2010.

2 Convenio $\mathrm{N}^{\circ} 87$ sobre "la libertad sindical y protección del derecho de sindicación" y convenio $\mathrm{N}^{\circ} 98$ sobre "el derecho de sindicación y negociación colectiva". Para un análisis de la negociación colectiva y la libertad sindical véase CAAMAÑo Rojo, Eduardo y UGARTE CATALDO, José Luis. Negociación colectiva y libertad sindical. Un enfoque critico. Santiago: LegalPublishing, 2008, pp. 13 y ss. Una visión histórica y jurídica se encuentra en MENGOD GIMENO, Rosa María. Libertad sindical. Efectos de la promulgación de los convenios 87 y 98 de la OIT, en la legislación chilena. Santiago: Departamiento de Derecho del Trabajo y de la Seguridad Social, Facultad de Derecho, Universidad de Chile, 2007, pp. 4 y ss.

${ }^{3}$ Gamonal Contreras, Sergio. Derecho colectivo del trabajo. Santiago: LexisNexis, 2007, p. 60. Otra definición, donde se explicitan sus atributos se encuentra en CAAMAÑo Rojo, Eduardo y UGaRTE CaTALDO, José Luis, op. cit. (n. 2), pp. 14-15. En efecto, señalan que es "el derecho que asiste a los trabajadores para constituir organizaciones, afiliarse o desafliarse a ellas, a darse su propia normativa sin intervención de terceros y, especialmente, el derecho al ejercicio de la actividad sindical por medio de aquellas acciones tendientes a la defensa y promoción de los intereses que le son propios, en particular, la negociación colectiva y la huelga".
} 
Roberto Cerón Reyes y Jorge Martínez Rivera / Cuestiones discutidas y discutibles: término de la empresa...

bajadores asalariados para la representación y defensa de sus intereses generales frente al empresario y sus organizaciones y, eventualmente, frente a cualquiera otros sujetos de carácter privado o público" ${ }^{\prime}$.

\section{UNA EVASIÓN ROCAMBOLESCA DE LA CUESTIÓN}

\subsection{EL CASO}

Mario Mancilla Oyarzún, empresario individual, recurre en contra de la Inspección del Trabajo de Punta Arenas, fundado en que hasta el 31 de diciembre de 2008 fue concesionario del servicio de recolección de residuos domiciliarios de la comuna de Punta Arenas, para lo que contaba con trabajadores que se desempeñaban en las funciones propias del servicio; estos, además, se encontraban sindicalizados en el "Sindicato $N^{\circ} 2$ empresa Mario Mancilla" con quienes mantenía contrato colectivo vigente. Que el 2 de enero de 2009 se puso término al "contrato de prestación de servicio de recolección y transporte de residuos sólidos domiciliarios" que unía al actor con el municipio de Punta Arenas, por término del plazo pactado en él. Basado en ello puso término a los contratos de trabajo de todos sus dependientes basado en el $N^{\circ} 5$ del artículo 159 del Código del Trabajo (CT), esto es, conclusión del contrato o servicio que dio origen al contrato para los que fueron contratados, salvo respecto de los 3 dirigentes sindicales del "Sindicato $N^{\circ} 2$ empresa Mario Mancilla", contra quienes se inició procedimiento de desafuero, el que en definitiva fue rechazado. Al tiempo de la interposición de la acción constitucional, el recurrente de protección no desarrolla actividad empresarial alguna como empresario individual en el mentado giro, pero continúa pagando la remuneración mensual a los tres dirigentes sindicales quienes no prestan servicio alguno.

Señala el peticionario que desde hace 11 meses (2 de enero de 2009) el "Sindicato $N^{\circ} 2$ empresa Mario Mancilla" ha dejado de cumplir los requisitos necesarios para su constitución por lo que solicitó a la Inspección del Trabajo de Punta Arenas, basado en el derecho general de petición del artículo $19 \mathrm{~N}^{\circ} 14$ de la Constitución Política de la República (CPR), accionara para su disolución como uno de los legitimados para hacerlo -los otros legitimados son los socios- ante los Tribunales del Trabajo. El órgano administrativo aludido por medio de Ordinario 1535, de 13 de noviembre de 2009, rechazó la solicitud incoada por lo que recurre de protección contra ella, pues, a su juicio, se trata de una resolución (acción) que vulnera sus derechos constitucionales garantizados en los numerales $2^{\circ}$ y $24^{\circ}$ del artículo 19, toda vez que el órgano fiscalizador actúa con pasmosa lenidad tratándose de las infracciones de los trabajadores y con implacable celo con las del empleador, amén, que es su patrimonio el que soporta la carga del pago de las remuneraciones de los directores sindicales.

\footnotetext{
${ }^{4}$ Palomeque López, Manuel Carlos y Álvarez de la Rosa, Manuel. Derecho del trabajo -16a edición-. Madrid: Centro de Estudios Ramón Areces, 2008, p. 308.

${ }^{5}$ Causa RIT N O-134-2008, RUC N 0840005385-6.
} 
En su informe a la Corte, la Inspección Provincial del Trabajo alegó que era necesario fijar un plazo prudencial previo a accionar ante el Tribunal por la disolución del sindicato, esto en razón de evitar prácticas antisindicales y guardar el debido equilibrio con el principio de libertad y autonomía sindical. De esta manera, la Dirección del Trabajo a través de su Departamento de Relaciones Laborales impartió instrucciones sobre la disolución por incumplimiento de los requisitos de constitución de las organizaciones sindicales, señalando que para proceder a la acción de disolución, previamente, se debía cumplir con un requisito temporal contenido en la Orden de Servicio $N^{\circ} 9$ de 2005 no contemplado expresamente en el artículo 297 CT, a saber: 1. Inactividad o receso de la organización por un período superior a dos años; 2 . Afiliación de menos de 8 socios durante el mismo período de dos años.

Asimismo -según la recurrida-, el plazo de dos años, "da cuenta de las múltiples situaciones referentes a la disolución de organizaciones sindicales" (?). Arguye, por último, que la Acción de Protección de marras busca soslayar una sentencia ejecutoriada confirmada por la Corte Suprema, que declaró inadmisible la unificación de jurisprudencia y, en consecuencia, no autorizó el despido de los trabajadores.

La Corte de Punta Arenas, por su parte, en un razonamiento sumarísimo se limita a constatar si se cumplen en el caso de marras los supuestos fácticos contenidos en el artículo 297 CT para hacer procedente la solicitud de disolución por los legitimados -la Inspección del Trabajo-, y que la Administración no está llamada a establecer criterios adicionales a los legales previos a cumplir con las obligaciones que le impone la ley laboral, por tanto, la Inspección del Trabajo ha vulnerado los derechos constitucionales del recurrente con su acción, vale decir, el Ordinario 1355 y su omisión de pedir la disolución, por lo mismo, se le otorga a la recurrida un plazo de 10 días desde que quede ejecutoriada la sentencia para accionar en tal sentido.

Así lo hizo la Inspección, y en sentencia ${ }^{6}$ de 20 de mayo último el Tribunal de Letras del Trabajo de Punta Arenas, acogió la solicitud de disolución del sindicato, ordenando que este sea borrado del Registro que al efecto lleva la Inspección, sus bienes sean destinados a la organización que señale el Presidente de la República y su liquidación se lleve a cabo por la persona que designe el Director Regional del Trabajo.

\subsection{EL PROBLEMA}

En el caso en estudio es evidente la existencia, aunque exiguo en socios, del sindicato y, a su vez, la posibilidad cierta, en virtud del derecho a la libertad sindical, del ejercicio de los derechos y fueros que el ordenamiento atribuye a ella. En este sentido, cobra especial relevancia la libertad colectiva de disolución o derecho de los sindicatos a disolverse, ya sea por acuerdo de sus afiliados o por causal de orden público ${ }^{7}$. La primera -causal de disolución voluntaria - en consonancia con lo prescrito en el artículo 296 del CT, procede por la mayoría

\footnotetext{
${ }^{6}$ Causa RIT Nº O-27-2008, RUC N 10-4-0019353-9.

7 Gamonal CONTRERAS, Sergio, op. cit. (n. 3), p. 94. Los restantes atributos de la libertad sindical son la libertad de: constitución, afiliación, sindical negativa, colectiva de reglamentación, colectiva de representación, colectiva de actuación sindical y colectiva de federación.
} 
absoluta de sus afiliados lo que, en el caso de autos, se reduce a dos de los tres dirigentes sindicales que aún conservaban el vínculo jurídico laboral, amparados en su fuero sindical, con la empresa. Por su parte, la segunda -causal de disolución de orden público- se encuentra establecida en el artículo 297 del CT y procede siempre y cuando exista un "incumplimiento grave de las obligaciones que le impone la ley [al sindicato] o por haber dejado de cumplir con los requisitos necesarios para su constitución", previo conocimiento de los tribunales del trabajo y a solicitud fundada de la Dirección del Trabajo o por cualquiera de sus socios.

Lo anterior permite plantear una serie de interrogantes en torno al caso, todas relacionadas con las posibilidades existentes para terminar con la organización sindical "fantasma" o al menos evitar que el fuero se convierta en una fuente de enriquecimiento injusto para los trabajadores. Ellas nos conducirán a tratar, obligadamente, algunos tópicos concernientes al derecho colectivo del trabajo. En efecto, ¿contempla el ordenamiento una solución menos engorrosa que la considerada ad supra (3 juicios distintos) para terminar la relación de trabajo cuando la empresa no continúa desarrollando actividad económica? Ahora, respecto de la causal de disolución de orden público del sindicato ¿están los socios obligados a pedir la disolución por esta causal cuando se cumple el supuesto de hecho del artículo 297 CT?, si no es asi ${ }^{8}$, ¿puede cumplir los fines por los que el ordenamiento le reconoce existencia jurídica un sindicato con tres afiliados? Aparejado a ello y al tenor del artículo 297 del CT ¡̨la Dirección del Trabajo puede -facultad- o debe-mandato- acudir a los tribunales de justicia cumplido el supuesto de hecho del artículo 297 CT? y, en el caso que sea su deber hacerlo ison vulneradas las garantías del $19 \mathrm{~N}^{\circ} 2$ y 24 de la CPR si no lo hace? o, más bien, ¿existe vulneración a la garantía del $19 \mathrm{~N}^{\circ} 3$ de la CPR al existir un interés del empleador sin la correspondiente acción?

\subsection{CONCEPTO DE EMPRESA Y EL FUERO}

Uno de los temas recurrentes de nuestra disciplina es el del concepto de empresa. La norma del artículo $3^{\circ}$ inciso $3^{\circ}$ reza: "Para los efectos de la legislación laboral y de seguridad social, se entiende por empresa toda organización de medios personales, materiales e inmateriales, ordenados bajo una dirección, para el logro de fines económicos, sociales, culturales o benéficos, dotada de una individualidad legal determinada" ha sido objeto de la más variada hermenéutica, así tribunales e iuslaboralistas desde sus respectivas trincheras han pretendido desentrañar cuándo nos encontramos frente a una empresa para efectos laborales y previsionales, situación a la que volveremos más adelante.

Traemos a colación el concepto de empresa, pues este tiene importancia capital en nuestra hipótesis consistente en que existe una solución al caso de marras más razonable y funcional que la obtenida, entendiendo por razonable aquella acorde con los intereses legítimos de las partes, por ende, merecedores de tutela jurídica, y por funcional aquella con costos de transacción menores que los expuestos ${ }^{9}$.

\footnotetext{
${ }^{8} \mathrm{~A}$ todas luces no se condice con las normas de constitución prescritas en los artículos 227 y 228 del CT.

${ }^{9}$ En teoría, el empleador habría debido pagar desde el término de la concesión que explotaba el equivalente a 16 remuneraciones para 3 trabajadores aforados, en total 48 remuneraciones hasta que se acogió la disolución del sindicato y se hizo posible su despido.
} 
Es un hecho de la causa que desde el momento en que venció la concesión administrativa cuya explotación daba razón de ser a la empresa se hizo imposible -para el empleador- la continuidad de la actividad lucrativa que realizaba, sin perjuicio de ello el sindicato se mantuvo vigente, pues el servicio de recolección de basura es un servicio público que solo puede ejercerse con autorización administrativa. En vista de esta imposibilidad, la estrategia judicial del empleador se centró en la disolución del sindicato. En este predicamento los artículos 296 y 297 CT se hacen cargo expresamente de la cuestión controvertida, que por tratarse de la limitación de derechos fundamentales -libertad sindical- la interpretación ha de ser restrictiva y no extensiva.

En base a estos artículos la doctrina ha. establecido que la disolución de los sindicatos puede provenir de dos fuentes, a saber, la autonomía colectiva (artículo 296 CT) o de causales disciplinarias o de sanción (artículo $297 \mathrm{CT}$ ) ${ }^{10}$, otra clasificación bajo los mismos supuestos es la que distingue entre causal voluntaria y de orden público ${ }^{11}$.

Ahora, respecto al caso en estudio, la ocurrencia de un hecho-vencimiento del plazo de la concesión- externo al sindicato no está contemplado como causal de disolución ${ }^{12}$, así se ha señalado "[Que] el trabajador para afiliarse a un sindicato de empresa, debe tener la calidad de dependiente de un determinado empleador, pero una vez ejercido, la relación del trabajador con la organización se sujeta a las normas propias de los sindicatos, entre otras a las de disolución de los mismos", en otros términos, para el cese del fuero ha de estarse a alguna de las normas sindicales que así lo dispongan, en la especie el juicio de desafuero. Considerando que todas las instancias judiciales no dieron lugar al desafuero que autorizara el despido ${ }^{13}$, tal y como se presentan los hechos se colige que la imposibilidad de continuar la actividad lucrativa por cualquier causa implica, al menos en este caso, que el empleador debe conformarse con mantener el empleo a quienes detentan la calidad de directores sindicales, mientras no sean los propios socios del sindicato o la Inspección del Trabajo respectiva quienes soliciten la disolución del mismo y, en consecuencia, el término del fuero.

Pero, a nuestro juicio, tal discusión es innecesaria pues la controversia no debía versar sobre la disolución del sindicato, por lo que la titularidad de la acción y todo lo relativo a ella no es más que un soslayo rocambolesco del quid de la cuestión, a saber, el término de la empresa en virtud del vencimiento de la concesión administrativa y el connatural término del fuero.

En este sentido el artículo 243 CT que regula el fuero de los directores, y que extrañamente no fue utilizado, contempla expresamente el término del fuero:

“Los directores sindicales gozarán del fuero laboral establecido en la legislación vigente, desde la fecha de su elección y hasta seis meses después de haber cesado en el car-

\footnotetext{
${ }^{10}$ TAPIA Guerrero, Francisco. "El Concepto de Empresa y los Derechos Sindicales en el Derecho Chileno del Trabajo", en: Estudios en homenaje al profesor William Thajer Arteaga. Santiago: Sociedad Chilena de Derecho del Trabajo y de la Seguridad Social, 1998, p. 241.

11 Gamonal, Cóntreras, Sergio, op. cit. (n. 3).

12 TAPIA Guerrero, Francisco, op. cit. (n. 10), pp. 235-236.

${ }^{13}$ No resulta relevante en este punto que el empleador haya utilizado una causal jurídicamente improcedente como era la del $159 \mathrm{~N}^{\circ} 5 \mathrm{CT}$, pues, como se verá, el juicio de desafuero per se era innecesario.
} 
Roberto Cerón Reyes y Jorge Martínez Rivera / Cuestiones discutidas y discutibles: término de la empresa...

go, siempre que la cesación en él no se hubiere producido por censura de la asamblea sindical, por sanción aplicada por el tribunal competente en cuya virtud deban hacer abandono del mismo, o por término de la empresa"14.

\subsection{EL TÉRMINO DE LA EMPRESA}

Como dijimos, la jurisprudencia y la doctrina han sido abundantes en el tratamiento de la empresa para efectos laborales y previsionales, siendo el ya citado artículo $3^{\circ}$ inciso $3^{\circ}$ del CT el objeto científico para ello. Pero, paradójicamente, el término de la empresa no se ha desarrollado como tal a propósito del concepto de empresa, sino preferentemente bajo la óptica del principio-regla de continuidad de la empresa, v.gr., casos de fusiones, adquisiciones, divisiones y otros fenómenos de reorganización de capital ${ }^{15}$.

Según UGARTE, la definición de empresa del artículo 3 inciso $3^{\circ} \mathrm{CT}$ no tiene en sí misma una relevancia específica que sea independiente de la de empleador, vale decir, "la persona natural o jurídica que utiliza los servicios intelectuales o materiales de una o más personas en virtud de un contrato de trabajo". Esta tesis resulta acertada en la medida que al derecho del trabajo solo interesan las empresas que tienen trabajadores, pues, es posible concebir emprendimientos que prescindan de ellos; toda vez que la empresa es solo la organización práctica de los factores productivos que hace el empleador, y el trabajo aquí es solo otro factor. Pero en el caso propuesto la empresa no se puede reducir sin más al concepto de empleador, puesto que es ella como organización de los factores productivos la que determina, por fallar uno de sus requisitos, que el empleador dejará de ser tal.

Aun no estando abordado el término de la empresa en la forma que nos interesa, estimamos con UGARTE que los elementos que contiene la definición del artículo $3^{\circ}$ inc. $3^{\circ} \mathrm{CT}$ son copulativos, es decir, que deben concurrir todos para que nos encontremos frente a una empresa para efectos laborales, esto es, el elemento material u organizativo y la individualidad legal determinada, si ellos se dan sin más hay empresa, si han existido y de forma sobreviviente cualquiera de ellos falla, simplemente ya no hay empresa, esta terminó ${ }^{16}$.

En el caso en estudio, ha vencido el plazo pactado para la concesión, que era el objeto para el que el empleador contrató a los trabajadores, ha cesado con ello la "finalidad económica". Sin perjuicio de ello, ha subsistido la individualidad legal, pues tratándose de un empresario individual, esta solo podría terminar con el fin de la persona.

Concluimos, entonces, que la empresa ha terminado para efectos jurídico laborales, desde el momento en que el empleador perdió la concesión y no pudo continuar con el desarrollo de la actividad lucrativa. Reconociéndole el propio ordenamiento del trabajo (artículo 243 CT) que en tal circunstancia no está obligado a mantener el empleo a los trabajadores aforados, pues terminada la empresa el fuero ha cesado de pleno derecho. La conclusión, ade-

\footnotetext{
${ }^{14}$ Las cursivas son nuestras.

15 TAPIA GUERrERo, Francisco, op. cit. (n. 10). En igual contexto y con un alcance, similar, empresa como extensión de la actividad del empleador, puede verse en: UGARTE CATALDO, José Luis. El Nuevo Derecho del Trabajo. Santiago: Editorial Universitaria, 2004, p. 84.

${ }^{16}$ UgarTe Cataldo, José Luis, op. cit. (n. 15), pp. 67 y ss.
} 
más, concuerda con la sistemática ${ }^{17}$ del CT en este sentido el artículo $201 \mathrm{CT}$ prescribe que cesada la causa que dio lugar al fuero maternal, este cesa de pleno derecho, a pari, terminada la empresa también ha de cesar el fuero de los directores del sindicato de empresa.

Por otra parte, la solución que implica "[el] término de la empresa" del artículo 243 CT, es la que más se adecua, concretamente, a una solución sensata del caso. Esto, porque se trata de una causal que opera por el solo ministerio de la ley, en otras palabras, no hace falta pronunciamiento judicial alguno que la califique previamente, lo que se torna coherente, pues es el empleador como coordinador de los factores productivos quien debe decidir si perseverará en su empresa y, por lo tanto, si requerirá o no trabajadores para ello (si no es así los despedirá por necesidades de la empresa) sin recurrir a los costos de un desafuero; corresponderá, por ende, al trabajador ejercer la acción para desvirtuar el cese de la empresa y que esta pervive.

Por último, esta hipótesis resulta conforme con el principio de la autonomía privada reconocido en nuestra Constitución Económica ${ }^{18}$, ya que las personas tienen garantizado el derecho a iniciar, desarrollar, terminar los emprendimientos que estimen convenientes y las normas de Derecho Colectivo no pueden convertirse en gravamen o traba a las lícitas decisiones que tome el empleador, menos aun si no existe justificación para ello ${ }^{19-20}$.

Probada nuestra tesis nada tiene que hacer aquí la Inspección del Trabajo y la disolución del sindicato es baladí. Sin embargo, dedicaremos la segunda parte del presente comentario al estudio de las facultades de la Dirección del Trabajo, en relación con la disolución de los sindicatos por razones disciplinarias o de orden público, su relación con el debido proceso que garantiza el artículo $19 \mathrm{~N}^{\circ} 3$ de la CPR y los eventuales problemas que de ello surgen.

\section{UNA TRÍADA ANECDÓTICA CON EFECTOS ESTRAMBÓTICOS}

\subsection{LA PERSONA FRENTE A LA ADMINISTRACION}

De los antecedentes de hecho y de derecho considerados para arribar a la decisión del caso en estudio, se encuentra aquel que guarda relación con las atribuciones de la Dirección del Trabajo delegables, por mandato legal, a la Inspección del Trabajo y sus oficinas regionales. En consonancia con lo prescrito por el DFL N² de 1967 que regula el funcionamiento

\footnotetext{
${ }^{17}$ AlCalde Rodrfguez, Enrique. Los principios generales del derecho. Santiago: Ediciones de la Universidad Católica de Chile, 2003 , p. 52.

${ }^{18}$ Artículos $19 \mathrm{~N}^{\circ} 16,21,23,24$, entre otros.

${ }^{19}$ La idea la tomamos de PALAVECINO CÁCERES, Claudio. Subcontratación. Santiago: Editorial Jurídica de Chile, 2006 , p. 16.

20 En el caso de marras por el menguado número de socios del sindicato, no existe justificación posible que impida al empleador ejercer su derecho a organizar los factores. Es más, la pervivencia del sindicato en esas circunstancias constituiría un abuso del derecho fundamental de libertad sindical por parte de sus socios; no abundamos en esta hipótesis, porque estimamos que las reglas son suficientes para resolver el conflicto sin que sea necesario analizar si el resultado del ejercicio del derecho resulta o no justificado conforme con los principios. Sin perjuicio de ello, en nuestro medio no se ha estudiado debidamente la posibilidad de abuso de los derechos fundamentales como categoría jurídica, menos tratándose de los laborales especificos e inespecificos, por sus titulares; seguimos a Atienza y Ruiz Manero en su planteamiento de que los derechos fundamentales, dan el ejemplo de la huelga, son relativos y susceptibles de abuso por sus titulares, salvo los que implican una abstinencia absoluta de los demás como el derecho a no ser sometido a torturas o tratos vejatorios. ATIENZA, Manuel y RUIZ MANERO, Juan. Ilícitos Atípicos. Madrid: Editorial Trotta, 2000, pp. 63-66.
} 
Roberto Cerón Reyes y Jorge Martínez Rivera / Cuestiones discutidas y discutibles: término de la empresa..

del mencionado servicio público, podemos señalar como atingentes al caso sublite, las siguientes facultades:

"Artículo 1 letra:

a) La fiscalización de la aplicación de la legislación laboral.

d) La supervigilancia del funcionamiento de los organismos sindicales y de conciliación, de acuerdo con las normas que los rigen.

Artículo 5 letra:

c) Velar por la correcta aplicación de las leyes del trabajo en todo el territorio de la República”.

Tales potestades pueden ser agrupadas en torno a las facultades "fiscalizadoras" de la Inspección del Trabajo las que, en cierto modo, se diferencian de las facultades "interpretativas". En cuanto a las primeras, relevancia cobra el alcance atribuible al vocablo "fiscalizar" en materia laboral administrativa. Para el profesor SOTO KLOSS el término en asunto no es otra cosa que “...sinónimo de controlar, comparar objetivamente si lo que percibimos por los sentidos se ajusta, se adecua, se conforma, con una medida o parámetro igualmente objetivo preexistente, esto es la ley y, en este caso, la ley laboral" 21.

Ahora bien, en el caso de marras el empleador acude a la Inspección del Trabajo regional para que, en virtud de su derecho de petición consagrado en el artículo $19 \mathrm{~N}^{\circ} 14$ de la CPR, se determine si de acuerdo con los antecedentes de hecho existentes y aportados por este, es posible el término del sindicato, conforme con el artículo 297 del CT, pues los legitimados para actuar en este tipo de situación son el referido organismo o "cualquiera de los socios" del sindicato. En efecto, dispone expresamente que procederá la disolución de la organización sindical por "incumplimiento grave de las obligaciones que le impone la ley" o "por haber dejado de cumplir con los requisitos necesarios para su constitución". Ante ello, existe un hecho evidente y desconcertante ante el cual se enfrenta el inspector laboral, cual es la existencia de una empresa sin actividad económica, con tres trabajadores los que, a su vez, componen el sindicato de la empresa, todos directores sindicales, sujetos a fuero para "representar a los trabajadores" que, paradójicamente, no existen. Estamos entonces, ante la presencia de un sindicato fantasma.

La operación de fiscalización, en virtud de las atribuciones arriba referidas, resultaría del todo sencilla, puesto que no existen trabajadores a los cuales representar -obligación impuesta de acuerdo con lo prescrito por el artículo 220 del CT-y, menos aun, está el quórum mínimo y suficiente indicado en el artículo 227 del citado texto legal, exhibiéndose de este modo la necesaria conformidad entre la ley laboral y el hecho concreto y, de paso, los presupuestos para que la Inspección del Trabajo presente "solicitud fundada" ante el juez laboral ${ }^{22}$ para disolver la organización sindical.

${ }^{21}$ SOTO KLOSS, Eduardo. "¿Es tan "delgada la línea que separa “fiscalizar” de “juzgar”?”, en: Gaceta Juridica, $N^{\circ} 331$, Santiago, enero 2008, pp. 35-42.

22 Según LizAMA "Además, se ha dicho que el ejercicio de funciones interpretativas, fiscalizadoras y de resguardo en la debida aplicación de la legislación social tiene dos alcances: uno, inhibe a la Dirección del Trabajo para pronunciarse sobre presupues- 
Sin embargo, aquí vienen las tres primeras curiosidades. Primero, el servicio en cuestión impone requisitos adicionales a los ya expresados, a través de una Orden con alcance nacional, a lo largo y ancho del país, donde señala una "inactividad o receso superior a dos años y/o afiliación de menos de ocho socios durante el mismo período" para presentar la solicitud de disolución, imponiendo criterios ajenos a los mencionados en la ley. Segundo, al agregar tales condicionantes y no actuar según los parámetros impuestos por el legislador para el ejercicio de su función fiscalizadora, incurre en una serie de infracciones a los principios esenciales que impregnan el actuar de la administración ${ }^{23}$. Tercero, al fiscalizar sin el deber de imponer una multa, pues nada se ha infringido, priva al administrado de acudir a la justicia para que ella sea la que finalmente arbitre lo que en derecho corresponda, ya que, literalmente, el legislador le ha cercenado la posibilidad de solicitar la disolución directamente ante el tribunal. En otras palabras, ante el gobernado y el magistrado se interpone, al modo de una Muralla China o un Muro de Berlín, la Inspección del Trabajo.

Lo precedentemente expuesto conlleva, obligadamente, a tratar las consecuencias no tan anecdóticas de aquellas curiosidades. Una guarda relación con la forma en que actúa la administración frente a la legalidad y, la otra, la privación, por cuenta y obra de la administración, al acceso a un procedimiento racional y justo que determine, con los antecedentes del caso, la disolución del sindicato.

\subsection{LA ADMINISTRACION FRENTE A LA LEGALIDAD}

Como todo servicio público, la Inspección del Trabajo se encuentra inserta en el cuadro general de la Administración Pública del Estado. Bajo ese prisma, además de estar sujeta a su propia regulación, está obligada al cumplimiento de una normativa general, tanto a nivel constitucional y legal, como órgano del Estado. Es por ello que ante un posible desvarío que se observe en su actuar, le son aplicables los principios y normas de derecho administrativo y constitucional.

Así las cosas, las infracciones legales y constitucionales del servicio en estudio se multiplican. Si se aparta de los principios constitucionales esenciales para la actuación de los órganos administrativos ${ }^{24}$ la Inspección del Trabajo, al desafiar a la legalidad común a todos los órganos del Estado, se convierte en una trasgresora de la misma.

\footnotetext{
tos fácticos que den origen o extingan una relación laboral o particular o los derechos que de ellas derivan, y dos, deja siempre a salvo el derecho de los particulares de recurrir ante el órgano jurisdiccional competente, sea ordinario o arbitral, para la solución de las controversias surgidas entre las partes por la aplicación de la legislación laboral", en: LizAMA PORTAL, Luis. La Dirección del Trabajo: Una explicación de su facultad de interpretar la legislación laboral chilena. Santiago: Fundación Facultad de Derecho, 1998, p. 41. Aquí, el resguardo jurisdiccional está ausente.

${ }^{23}$ Así los denomina el profesor de Derecho Administrativo Juan Carlos Ferrada Bórquez. Para él, tales son el principio de servicialidad (artículo 1 de la CPR), supremacía constitucional (artículo 6), juridicidad (artículos 7 y 65), responsabilidad (artículo 7), probidad (artículo 8), objetividad y neutralidad política (artículo 38) y control jurisdiccional (artículo 38). FERRADA BORQueZ, Juan Carlos. "Los principios estructurales del derecho administrativo chileno: un análisis comparativo", en: Revista de Derecho $\mathrm{N}^{\circ}$ 221-222. Concepción: Universidad de Concepción, 2007, p. 114.
}

24 Ibid. 
Roberto.Cerón Reyes y Jorge Martínez Rivera / Cuestiones discutidas y discutibles: término de la empresa...

Sin perjuicio que el tema excede las líneas de este comentario, podemos poner nuestra atención en algunos puntos, de modo de exhibirlos en la palestra, pero no para acabar su explicación. Nos referimos al principio de legalidad y las potestades de la administración y su control.

\section{a) El principio de legalidad}

El principio de legalidad es, en cierto modo, el cortafuego frente a la actuación de la administración. GARCÍA DE ENTERRÍA lo define como "el sometimiento a la Ley de la administración, a cuya ejecución limita sus posibilidades de actuación" ${ }^{25}$. En nuestro ordenamiento jurídico, tal principio se encuentra recogido en los artículos $6^{26}$ y $7^{27}$ de la Constitución y en el artículo $2^{28}$ de la Ley Orgánica Constitucional de Bases Generales de la Administración del Estado.

En el caso de autos, la vulneración al principio se observa y se bifurca en dos manifestaciones. La primera es el quebrantamiento strictu sensu de la legalidad, es decir, la inadecuada actuación conforme lo disponen las leyes y, segundo, aquello que permite la actuación administrativa, o sea, las potestades del servicio administrativo. Vamos por parte y por el principio.

En este caso, la infracción al principio de legalidad se observa a través de la imposición de requisitos extra legem para la disolución del sindicato, ajenos y distintos a los preceptuados en el artículo 297 del CT que son, a nuestro parecer y al de la Corte de Apelaciones de Punta Arenas; los únicos posibles. Cedamos la palabra a esta última:

"Quinto: Que la ley solo exige, para pedir la disolución de un Sindicato, que este deje de cumplir los requisitos necesarios para su constitución. No hay otra exigencia. No se fijan plazos. La Dirección del Trabajo, a través de la Orden $\mathrm{N}^{\circ} 9$, citada por las partes, se ha limitado a señalar criterios nacionales, que a juicio de estos sentenciadores, no son vinculantes para regular las actuaciones de las Inspecciones Provinciales".

Además, lo anterior constituye una infracción al derecho constitucional consagrado en el $19 \mathrm{~N}^{\circ} 2$ del Código Político, el cual resguarda, entre otras cosas, la igualdad ante la ley. La misma Corte de Apelaciones lo reconoce: "Undécimo: Que la actuación y omisión de la Inspección Provincial del Trabajo ha sido arbitraria e ilegal, al afectar las garantías

\footnotetext{
25 Garcla de Enterrfa, Eduardo y Ramón Fernández, Tomás. Curso de Derecho Administrativo. I -12a edición-. Madrid: Thomson Civitas, 2004, p. 441. PANTOJA BAUZÁ, Rolando. El Derecho Administrativo. Santiago: Editorial Jurídica de Chile, 1984.

${ }^{26}$ Artículo 6 "Los órganos de la Constitución del Estado deben someter su acción a la Constitución y a las normas dictadas conforme a ella y garantizar el orden institucional de la República".

27 Artículo 7 "Los órganos del Estado actúan válidamente previa investidura regular de sus integrantes, dentro de su competencia y en la forma que prescriba la ley...".

${ }^{28}$ Artículo 2 "Los órganos de la Administración del Estado someterán su acción a la Constitución y a las leyes. Deberán actuar dentro de su competencia y no tendrán más atribuciones que las que expresamente les haya conferido el ordenamiento jurídico. Todo abuso o exceso en el ejercicio de sus potestades dará lugar a las acciones y recursos correspondientes".
} 
fundamentales del artículo $19 \mathrm{~N}^{\circ} 2$ y 24 de la Constitución Política, motivo por el cual, el recurso será acogido para poner remedio al mal causado...".

\section{b) Las potestades de la administración y su control}

Una segunda dimensión del principio de legalidad es aquella que, indefectiblemente, se relaciona con su actuar, el cual está legitimado por el hecho de ser un poder público, dotado de los atributos constitucionales y legales para imponer, en aras del bien común, determinadas prescripciones de conducta a los administrados. En este sentido, la actuación de la administración admite dos grandes clasificaciones: actuación por potestades regladas y actuación por potestades discrecionales. Ambas se diferencian, grosso modo, por la existencia o ausencia de una regulación de la forma en como deben ejecutar las potestades los órganos administrativos ${ }^{29}$.

Si aplicamos tal distinción a las potestades de la Inspección del Trabajo, se admite que las facultades fiscalizadoras corresponden al segundo grupo, o sea, a las potestades discrecionales, ya que nada se dice sobre la forma en como deben ser ejecutadas, apuntándose solo a los medios de los cuales se puede servir ${ }^{30}$ para su ejecución.

Frente a tamaño y válido margen de acción, una pauta insoslayable en su actuar es la primacía del interés público. Se ha sostenido que "En este sentido, en el campo de la gestión de los intereses públicos por los órganos de la Administración del Estado, el Derecho Administrativo es el dispuesto en el ordenamiento para regular las relaciones jurídicas, estableciendo los mecanismos para proteger los intereses públicos, pero garantizando al mismo tiempo los derechos de los particulares" 31.

Luces sobre este interés público son, a nuestro juicio, el principio de servicialidad del Estado, consagrado en el artículo 1 inciso $4^{32}$ de la constitución y el de probidad, prescrito en el artículo $8^{33}$ de la referida carta, entre otros. Ellos facilitan el entendimiento y finalidad

\footnotetext{
${ }^{29}$ GARClA DE ENTERRÍ, Eduardo y RAMÓN FERNÁNDEZ, Tomás, op. cit. (n. 25), p. 458 y ss.

${ }^{30}$ Falta un estudio acucioso que aborde la naturaleza jurídica de la función fiscalizadora de la Dirección del Trabajo. En el ejercicio de su función fiscalizadora el Inspector del Trabajo está autorizado: a) Para ingresar libremente y sin previo aviso, a cualquier hora, en todos los centros y lugares de trabajo (artículo 24 del DFL No 2 de 1967); b) Para requerir de los empleadores toda la documentación necesaria para cumplir su labor inspectiva (artículo 31); c) Para requerir el auxilio de la fuerza pública para el desempeño de sus funciones (artículo 26); d) Para efectuar requerimientos y extender actas de infracción u obstrucción (artículos 23 y 25); e) Para ordenar la suspensión inmediata de las labores que constituyan un peligro inminente para la vida o salud de los trabajadores y cuando constaten la ejecución de trabajos con infracción a la legislación laboral (artículo 28); f) Para citar empleadores, trabajadores, directores sindicales o a los representantes de unos y otros, con el objeto de procurar solución a los asuntos que se le sometan en el ejercicio de sus funciones, o que deriven del cumplimiento de disposiciones legales o a fin de prevenir posibles conflictos (artículo 29); g) Para cursar multas administrativas y ordenar la clausura de un establecimiento o una faena, en caso de infracción a las normas laborales, previsionales o de higiene y seguridad en el trabajo que les compete fiscalizar (artículos 34 y 506 del Código del Trabajo).

31 Ferrada Borquez, Juan Carlos, op. cit. (n. 25), p. 116.

32 "El Estado está al servicio de la persona humana y su finalidad es promover el bien común, para lo cual debe contribuir a crear las condiciones sociales que permitan a todos y a cada uno de los integrantes de la comunidad nacional su mayor realización espiritual y material posible, con pleno respeto a los derechos y garantías que esta Constitución establece".

33 "El ejercicio de las funciones públicas obliga a sus titulares a dar estricto cumplimiento al principio de probidad en todas sus actuaciones".
} 
del interés público. Si el Estado no está al servicio de la persona humana, el Estado, simplemente, está a su propio servicio ${ }^{34}$.

Así las cosas, frente a la posibilidad real y cierta, tal como sucedió en el caso, de rechazar los antecedentes presentados por el empleador para que la Inspección del Trabajo solicitara ante el juzgado del trabajo la disolución del sindicato, y pese a los elocuentes, evidentes y fundados hechos, el servicio administrativo se apartó y olvidó por completo las primeras y fundantes finalidades de sus función fiscalizadora. Frente a la primacía de la persona, se impuso la primacía de la libertad sindical, que para el caso se torna abstracta, inexistente, inoperante y fantasmagórica ${ }^{35}$.

El segundo punto involucrado es aquel que guarda relación con las posibilidades de control frente al uso y abuso de las potestades discrecionales. Aquí baste señalar dos cuestiones, ambas muy controvertidas y sin ánimo de acabar su explicación. Primeramente, en el caso particular del artículo 297 del Código del Trabajo, no existe posibilidad alguna de revisar la decisión de la Inspección del Trabajo frente a la eventualidad, hecha cierta en el caso de marras, del rechazo de los antecedentes que, a su juicio, no ameriten el calificativo de "fundados". O sea, el servicio no tiene ningún nivel de control, ya sea interno o externo, lo que amuralla al particular ante un servicio que puede errar, tal como las personas.

En segundo término, lo anterior permite sostener que estamos ante un vacío legal y, en consecuencia, de lege ferenda, pues es al existir fiscalización, pero no una multa, el administrado no tiene ninguna instancia a la cual acudir para someter el acto administrativo a una revisión jurisdiccional ${ }^{36}$, lo que representa una fuerte contradicción con el principio constitucional de control jurisdiccional, establecido en el artículo 38 de la constitución ${ }^{37}$.

Si bien este y otros puntos forman parte del espinudo tópico del Derecho Administrativo Sancionador, existe una diferencia, cual es la ausençia de sanción ante una legítima fiscalización. Asimismo, ante ausencia de control estamos, también, ante ausencia de jurisdicción que vele por la correcta aplicación de la ley, lesionándose el derecho constitucional al debido proceso.

\subsection{LA ADMINISTRACIÓN FRENTE AL DEBIDO PROCESO}

Según lo señalado por la doctrina constitucional, la administración del Estado, en virtud de lo dispuesto en los artículos 6 inciso primero y segundo ${ }^{38}$ y el artículo 5 inciso se-

\footnotetext{
34 Verdugo Marinkovic, Mario; Pfeffer Urquiaga, Emilio; Nogueira Alcaldé, Humberto. Detecho Constitucional. Tomo I -2a edición-. Santiago: Editorial Jurídica de Chile, 2005, pp. 112-113.

35 Véase nota 20.

${ }^{36} \mathrm{Si}$ operara sanción, no hay problemas, pues es el propio Código del Trabajo contempla la posibilidad de reclamación ante los tribunales (artículo 503).

37 Román CORDERo, Cristián. "Los principios del derecho administrativo sancionador", en: Revista de Derecho Público, vol. 69, pp. 24 y ss. Santiago: Universidad de Chile, 2007.

${ }^{38}$ Artículo 6 "Los órganos de la Constitución del Estado deben someter su acción a la Constitución y a las normas dictadas conforme a ella y garantizar el orden institucional de la República.

Los preceptos de esta Constitución obligan tanto a los titulares o integrantes de dichos órganos como a toda persona, institución o grupo."
} 
gundo, se encuentra sujeta al deber de respeto y promoción de los derechos humanos ${ }^{39}$, por lo que la Inspección del Trabajo, como órgano administrativo, está obligada, en el marco de su actuación, a procurar el adecuado equilibrio entre aquella y la protección constitucional a las personas ${ }^{40}$.

Lo anterior se torna apremiante cuando, como en el caso de autos, no existe posibilidad alguna de revisión jurisdiccional directa acudiéndose, entonces, a la vía indirecta del recurso de protección. Como apunta ALDUNATE:

"Esto implica, por una lado, reconocer una amplia justiciabilidad de todos los actos de los órganos de poder ejecutivo $\mathrm{y}$, también, la necesidad de reconocer instrumentos procesales adecuados para la tutela de los derechos frente al actuar de la administración. Como se señala más abajo, en esta materia el recurso de protección, si bien pudo estimarse en su momento un avance respecto de la situación histórica precedente, ha petrificado el desarrollo del control judicial de los actos del ejecutivo en sede jurisdiccional ordinaria" 41 .

De esta manera, una vía extraordinaria salvaguarda los derechos de los gobernados ante las actuaciones de los gobernantes. Sin embargo y volviendo al especialísimo caso del artículo 297, la actuación de la Inspección del Trabajo, fundada en el precepto señalado, representa una lesión al debido proceso. En este aspecto, la corte no hizo referencia alguna a este punto, ya que auxiliándose en el principio de legalidad determinó la arbitrariedad e ilegalidad de la actuación del organismo público.

Sostenemos que se lesiona el principio enunciado por cuanto el administrado se ve imposibilitado de acceder a una protección legal que permita arbitrar la situación contenida en el tantas veces citado artículo 297 del CT, privándosele, al tenor del artículo $19 \mathrm{~N}^{\circ} 3$ de la Constitución, de las "garantías de un procedimiento y una investigación racionales y justos", al no existir el derecho de acción que consienta someter al control jurisdiccional la decisión tomada por el organismo público ${ }^{42}$, situación que también se encuentra garantizada por el precepto constitucional citado, en su inciso primero ${ }^{43}$.

Ahora bien, dicha privación es consecuencia de una técnica legislativa defectuosa y ausente. Defectuosa, pues no se consideró la ocurrencia de la situación fáctica y jurídica presentada. Ausente, ya que no existe una norma legal que permita acceder "ordinariamente" a un órgano jurisdiccional. "Empero, "extraordinariamente" la Judicatura logró arribar a una solución que conciliara adecuadamente los hechos con el derecho. Sucedió, como tantas otras veces, lo que Cerdán de Tallada escribiera allá por el siglo XVI: “el buen juez hace buenas las malas leyes".

\footnotetext{
${ }^{39}$ Artículo 5 "El ejercicio de la soberanía reconoce como limitación el respeto a los derechos esenciales que emanan de la naturaleza humana. Es deber de los órganos del Estado respetar y promover tales derechos, garantizados por esta Constitución, así como por los tratados internacionales ratificados por Chile y que se encuentren vigentes".

${ }^{40}$ Aldunate Lizana, Eduardo. Derechos fundamentales. Santiago: LegalPublishing, 2008, p. 183.

41 Aldunate Lizana, Eduardo, op. cit. (n. 40), p. 194.

42 Verdugo Marinkovic, Mario, Pfeffer Urquiaga, Emilio, Nogueira AlCAlÁ, Humberto. op. cit. (n. 34), pp. $222-223$.

43 Maturana MiQuel, Cristian. Disposiciones comunes a todo procedimiento. Santiago: Universidad de Chile, Facultad de Derecho, 2008. AlCALde RodríGUeZ, Enrique, op. cit. (n. 17), p. 171 y ss.
} 


\section{BIBLIOGRAFÍA}

AlCalde Rodrf́guez, Enrique. Los principios generales del derecho. Santiago: Ediciones Universidad Católica de Chile, 2003.

Aldunate LizaNA, Eduardo. Derechos fundamentales. Santiago: LegalPublishing, 2008.

ATIENZA, Manuel y Ruiz MANero, Juan. Ilícitos Atípicos. Madrid: Editorial Trotta, 2000.

CaAmaño Rojo, Eduardo y UGarte CATAldo, José Luis. Negociación colectiva y libertad sindical. Un enfoque critico. Santiago: LegalPublishing, 2008.

FERRADA BORQUEZ, Juan Carlos. "Los principios estructurales del derecho administrativo chileno: un análisis comparativo", en: Revista de Derecho, N²21-222, Concepción: Universidad de Concepción, pp. 99-134.

Gamonal Contreras, Sergio. Derecho colectivo del trabajo. Santiago: LexisNexis, 2007.

Garcf́a de ENTERrfa, Eduardo y RaMón FERnÁNDeZ, Tomás. Curso de Derecho Administrativo. I -12a edición-. Madrid: Thomson Civitas, 2004.

LIZAMA PORTAL, Luis. La. Dirección del Trabajo: Una explicación de su facultad de interpretar la legislación laboral chilena. Santiago: Fundación Facultad de Derecho, 1998.

Maturana Miquel, Cristian. Disposiciones comunes a todo procedimiento. Santiago: Universidad de Chile, Facultad de Derecho, 2008.

MENGOD Gimeno, Rosa María. Libertad sindical. Efectos de la promulgación de los convenios 87 y 98 de la OIT, en la legislación chilena. Santiago: Departamento de Derecho del Trabajo y de la Seguridad Social, Facultad de Derecho, Universidad de Chile, 2007. 32p.

PALAVECINO CÁCERES, Claudio. Subcontratación. Santiago: Editorial Jurídica de Chile, 2006.

Palomeque López, Manuel Carlos y Álvarez de la Rosa, Manuel. Derecho del trabajo -16a edición-. Madrid: Centro de Estudios Ramón Areces, 2008.

Pantoja BAUZÁ, Rolando. El Derecho Administrativo. Santiago: Editorial Jurídica de Chile, 1984.

ROMÁN CORDERO, Cristián. "Los principios del derecho administrativo sancionador", en: Revista de Derecho Público, vol. 69, pp. 24-34. Santiago Universidad de Chile, 2007.

SOTO KLOSS, Eduardo. “¿Es tan "delgada la línea que separa "fiscalizar” de "juzgar”?", en: Gaceta Juridica, $N^{\circ} 331$, Santiago, enero 2008, pp. 35-42.

Tapia Guerrero, Francisco. "El Concepto de Empresa y los Derechos Sindicales en el Derecho Chileno del Trabajo", en: Estudios en homenaje al profesor William Thayer A., Santiago: Sociedad Chilena de Derecho del Trabajo y de la Seguridad Social, 1998.

UGarte CATAldo, José Luis. El Nuevo Derecho del Trabajo. Santiago: Editorial Universitaria, 2004.

Verdugo Marinkovic, Mario; Pfeffer Urquiaga, Emilio; Nogueira AlCalÁ, Humberto. Derecho Constitucional, Tomo I -2a edición-. Santiago: Editorial Jurídica de Chile, 2005. 